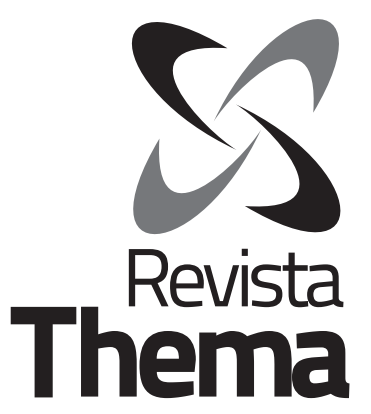

\title{
O Currículo do PROEJA no Curso de Habilidades Básicas em Panificação
}

\author{
Krischina Aplevicz* \\ Patrícia Matos Scheuer**
}

\begin{abstract}
Resumo: A partir do perfil do aluno PROEJA (Programa Nacional de Educação Profissional Integrado à Educação Básica na Modalidade Educação de Jovens e Adultos) e das concepções de currículo, descreve-se a necessidade de elevar o nível de escolaridade e qualificar os trabalhadores destinados a atuarem na área da panificação. O currículo do curso foi elaborado a partir dos estudos feitos por uma comissão de docentes envolvidos com a área de panificação. É necessário ocorrer uma mobilização para que o currículo seja prático e consiga integrar as atividades escolares com a sociedade e o mundo do trabalho. Assim, com intuito de ir ao encontro do exercício de uma educação emancipatória, é implantado o curso de Habilidades Básicas em Panificação.
\end{abstract}

Palavras-chave: PROEJA, educação profissional, currículo, panificação.

\begin{abstract}
Based on PROEJA's (National Program for the integration between Professional and Basic Education for young people and adults) student profile and on the concepts of curriculum, the need to boost the educational and qualifications levels of those workers aimed at working in baking area is described. The course curriculum was prepared based on studies done by a committee composed of teachers involved in the academic baking area. In order to assure a practical curriculum, able to integrate the school activities with Society and working practice, there must occur a mobilization. Thus, in order to achieve the exercise of an emancipatory education, it is deployed the course Basic Skills in Baking.
\end{abstract}

Key words: professional education, curriculum, baking.

\footnotetext{
* Doutora em Ciência dos Alimentos pela Universidade Federal de Santa Catarina, UFSC, Brasil.krischina@ifsc.edu.br.

** Mestre em Ciência dos Alimentos. patricias@ifsc.edu.br.
} 


\section{Introdução}

No Brasil, a Educação de Jovens e Adultos (EJA), no decorrer da história, tem sido colocada num segundo plano nas Políticas Públicas, o que, muitas vezes, tem gerado várias dificuldades para se desenvolver um projeto político-pedagógico voltado às reais necessidades dos jovens e dos adultos. Dentre elas, pode-se apontar a ausência de recursos para investir na estruturação adequada das salas de aula, na formação profissional dos educadores e na implementação de pesquisas em EJA para melhoria do trabalho docente nessa modalidade de ensino, evitando a infantilização da prática pedagógica (ROSA, PRADO, 2008).

A EJA no Brasil tem sido construída por dois tipos de movimentos. O primeiro deles é constituído pelo próprio grupo demandatário dessa educação, aqueles que não tiveram a oportunidade de passar por processo de escolarização regular. O outro movimento é o dos educadores de EJA, que é formado por um conjunto de pessoas, grupos, movimentos, órgãos públicos e privados que se dedicam a enfrentar essa demanda social. Não é um movimento articulado nas suas práticas e nas suas concepções, mas é um movimento articulado na vontade política de corrigir uma injustiça social (DURANTE, 1998).

O Brasil tem 12,9 milhões de pessoas analfabetas, segundo o IBGE (Instituto Brasileiro de Geografia e Estatística) com base em dados de 2011. A taxa de analfabetismo em 2011 foi mais alta entre as pessoas com mais de 25 anos. Do total de pessoas analfabetas, 96,1\% estavam nessa faixa etária. Entre as pessoas com mais de 50 anos a taxa é de $18,6 \%$ (IBGE, 2012). No processo de indução de políticas públicas que buscam a universalização da educação básica para a população brasileira, oriunda das classes populares, o PROEJA emerge como uma possibilidade de acesso e inclusão de jovens e adultos trabalhadores com histórico de descontinuidade escolar, bem como de exercício do direito à educação por esses sujeitos (BRASIL, 2007).

O intuito do PROEJA-FIC (Formação inicial e continuada) Ensino Fundamental é de integrar conhecimentos da educação geral com a formação profissional inicial e continuada, por meio de metodologias adequadas aos tempos e espaços da realidade dos sujeitos sociais que constituem o público beneficiário. Dessa forma, o grande desafio desse programa é construir uma proposta pedagógica que contemple, em sua organização curricular, a dimensão do trabalho e a elevação de escolaridade, tendo como referência, o perfil dos estudantes e as expectativas que esses tiveram anteriormente. E, para que tal desempenho seja alcançado, o PROEJA tem seus alicerces na convergência de três campos da Educação que consideram: a formação para atuação no mundo do trabalho; o modo próprio de fazer a educação, considerando as expectativas dos sujeitos jovens e adultos (EJA); e a formação para o exercício da cidadania (Educação Básica) (BRASIL, 2007).

Ao se tratar da EJA, Oliveira (2002), considerou não apenas a questão de especificidade etária, mas, principalmente, a de especificidade cultural. Os sujeitos dessa modalidade de educação frequentemente apresentam uma trajetória de exclusão da escola, trajetória esta muitas vezes marcada por reprovações, evasões, ou seja, podem ser considerados como produtos do fracasso do sistema escolar em garantir escolaridade básica completa para toda a população. Além disso, deve-se também considerar que o sujeito EJA está inserido no mundo do trabalho e das relações interpessoais, trazendo consigo experiências, conhecimentos acumulados e reflexões sobre o mundo externo, sobre si e sobre as outras pessoas (OLIVEIRA, 
1999), ou seja, situações de aprendizagem peculiares que precisam ser contempladas pelos currículos das instituições de ensino-aprendizagem.

O conhecimento que constitui o currículo está vitalmente envolvido naquilo que somos e naquilo que nos tornamos: nossa subjetividade e nossa identidade (SILVA, 1999).

Segundo Nóvoa (1988) há seis princípios que deveriam servir de orientação a qualquer currículo para formação de jovens e adultos: o adulto em situação de formação é portador de uma história de vida e de uma experiência profissional; formação é sempre um processo de transformação individual na tripla dimensão do saber, do saber fazer e do saber ser; a formação é sempre um processo de mudança institucional; formar não é ensinar às pessoas determinados conteúdos, mas sim trabalhar coletivamente em torno da resolução de problemas; a formação deve preocupar-se em desenvolver nos jovens e adultos as competências necessárias para mobilizarem em situações concretas os recursos teóricos e técnicos adquiridos; o homem caracteriza-se, sobretudo, pela capacidade de ultrapassar as situações pelo que consegue fazer com que os outros fizeram dele.

Assim, o currículo escolar deve ser construído a partir do conjunto das relações sociais estabelecidas pelos trabalhadores, setor produtivo e sociedade. Nessa construção, precisa-se levar em consideração os conhecimentos, as experiências dos sujeitos, bem como suas diversidades. Dessa forma, o currículo precisa expressar claramente essas relações com seus princípios, programas, metodologias e não se constituir apenas como uma série ordenada de conteúdos (BRASIL, 2007). Para se pensar currículo é preciso perguntar-se quais são os valores e os conhecimentos da cultura pública atual que merecem ser trabalhados na instituição de ensino, como identificá-los e quem os define (RIBEIRO, 2008).

Na construção de práticas pedagógicas com adultos, Moll (2008) afirmou três ideias que considera significativas para sala de aula: a consciência de que os homens e mulheres jovens e adultos não são tábulas rasas, mas portam um sem-número de experiências sociais, culturais, afetivas que lhe permitiram acúmulo de saberes em diferentes campos epistemológicos; a convicção de que a condição de analfabeto não implica nenhum tipo de patologia, déficit ou deficiência, e de que o analfabetismo não é uma expressão individual de fracasso, mas expressão de uma forma de exclusão socialmente construída; a compreensão de que a leitura da palavra escrita é impossível descontextualizada da leitura do mundo, ou seja, as palavras estão cravejadas de mundo e de significações produzidas no universo individual e social.

Sendo assim, a proposta curricular para EJA deve ser considerada como instrumento de apoio para a organização e reforma de um currículo voltado às reais necessidades regionais e às comunidades escolares, mesmo porque a EJA tem essencialmente um caráter político, que deve ser considerado na organização do currículo (ROSA, PRADO, 2008). 


\section{Objetivo}

Este artigo descreve a importância do currículo profissional do Programa de Educação de Jovens e Adultos (PROEJA) no curso de Ensino Fundamental (FIC)/ Habilidades Básicas de Panificação, no Instituto Federal de Educação, Ciência e Tecnologia de Santa Catarina (IFSC-Campus Florianópolis-Continente), como forma de contribuir para a garantia de acesso à educação básica, que auxilia o desenvolvimento sócio-econômico e a redução das desigualdades sociais. Tendo como base de estudo a Escola Morar Bem, o objetivo dessa pesquisa foi elaborar e vivenciar uma proposta de currículo PROEJA-FIC, integrando educação básica e educação profissional, de forma a capacitar o aluno cidadão profissionalmente.

\section{Metodologia}

O currículo do curso foi elaborado a partir dos estudos feitos por uma comissão de docentes envolvidos com a área de panificação e da realização de uma oficina prática entre os docentes do IFSC e da Escola Morar Bem do bairro Serraria, em São José. A oficina consistiu de uma aula prática de panificação para os professores da Escola Morar Bem, com o objetivo de verificar a realidade das aulas dos alunos, no laboratório de panificação, para possibilitar aos docentes listarem as habilidades necessárias ao aluno egresso. 


\section{Resultados}

A comunidade Morar Bem surgiu com objetivo de reassentamento de famílias que viviam em habitações precárias em área de risco no município de São José, caracterizada por pessoas de baixa renda, sem escolaridade e sem capacitação profissional. Ou seja, uma comunidade carente em aspectos econômicos, sociais e políticos.

O perfil dos alunos do PROEJA de São José - Formação Inicial e Continuada (FIC)/ Habilidades Básicas em Panificação foi delineado a partir da aplicação de um questionário em 15 alunos.

A faixa etária dos alunos está ilustrada na Figura 1. Pode ser observado que a maioria dos alunos está entre 24-30 anos. Apenas um aluno está abaixo desta faixa, este com 17 anos.

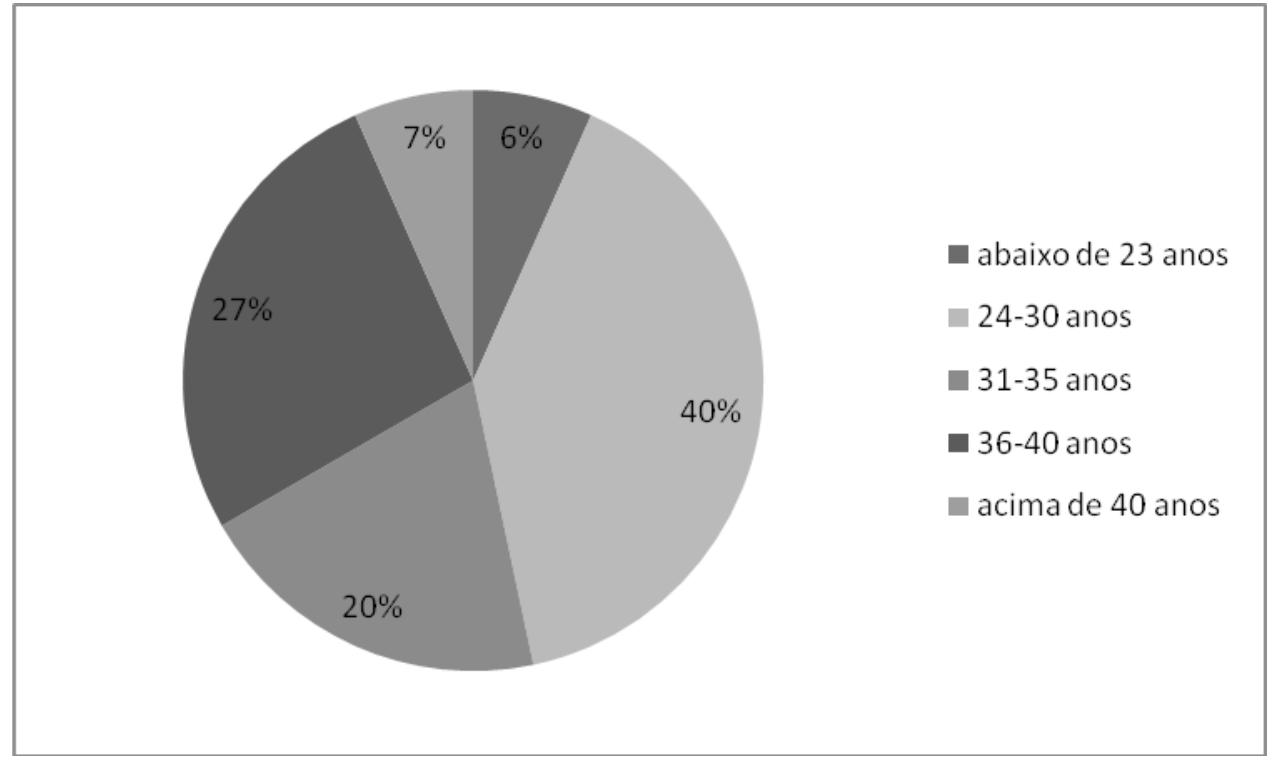

Figura 1: Faixa etária dos alunos do curso de Habilidades Básicas em Panificação.

Nessa turma, $73 \%$ do total dos alunos estavam afastados da escola por aproximadamente 16 anos, sendo que outros oscilam entre 2 e 4 anos (7\%) e 8 e 15 anos (20\%). A maioria dos alunos vem do ensino regular de escolas públicas (73\%); ensino supletivo ou outro de educação de jovens e adultos (27\%). Do total, $73 \%$ dos alunos relataram que nunca frequentaram cursos de formação inicial ou outro de qualificação profissional. O restante afirmou que já os fizeram no local de trabalho ou em escolas de formação profissional pública ou privada.

Para isso o aluno ingressante no PROEJA deve ser tratado como vencedor, pois o mesmo traz a bagagem histórica de fracasso e derrota (SANTOS, 2006). Essa é uma questão importante que permeia toda a construção e a execução do currículo na escola, pelo fato de haver a necessidade contínua de persuasão, conquista cativante e lúdica, para manter o educando motivado e presente nas atividades escolares, as quais incentivarão o exercício na sociedade. É papel da escola, portanto: orientar na seleção dos saberes, "encantar o aluno" e preparar o aluno para autonomia, para que ele crie, aprenda, opere e ajuste as condições à melhoria das condições de vida. 
De acordo com Santos (2006), o aluno da EJA foi expulso da escola regular ou a ela não chegou. Está fora da idade considerada "certa"; na maioria das vezes é um aluno que trabalha, ou está à procura do trabalho, não tendo tempo disponível, principalmente no que os professores consideram como tempo ideal para aprofundar seus estudos. Diante disso, os alunos da EJA são a própria desordem da escola regular e explicitam, desvendam os fracassos desse modelo "ideal" escolar.

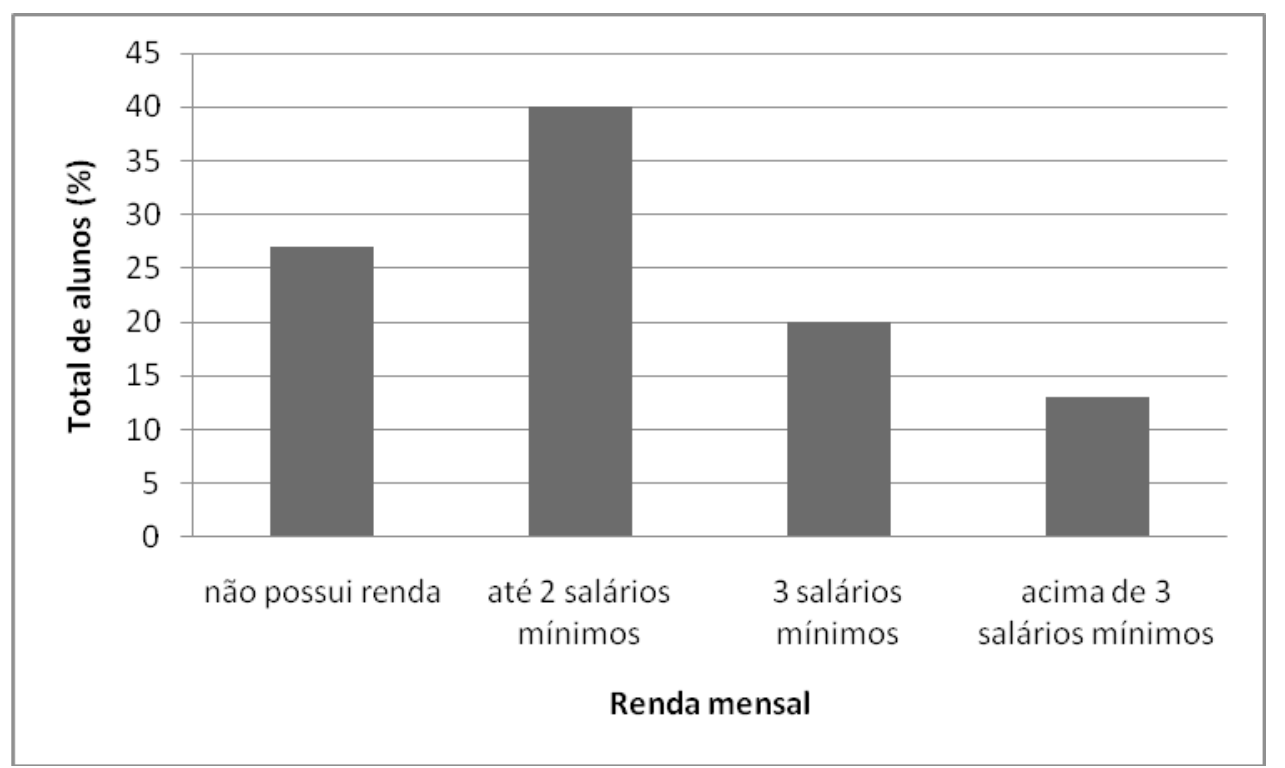

Figura 2: Renda mensal dos alunos do curso de Habilidades Básicas em Panificação.

Quanto à renda mensal, 40\% dos alunos declararam receber até dois salários mínimos; $27 \%$ até 3 salários mínimos e 20\% alunos acima disso. O restante dos alunos relatou não possuir renda mensal.

De modo geral, a família dos estudantes é composta por no mínimo 3 pessoas. Entretanto, destacam-se estudantes com famílias de 5 ou mais membros (67\%). Em relação ao retorno à escola e às expectativas quanto ao PROEJA-FIC os alunos responderam principalmente que pretendem conseguir um emprego a partir da conclusão do ensino fundamental e da formação profissional oferecida (47\%); outros pretendem empreender na área (20\%).

Os alunos trabalhadores exercem atividades, em geral, diferentes da formação profissional oferecida ( 8 alunos), e apenas 1 aluno trabalha em área relacionada ao curso, enquanto 6 alunos não trabalham ou estão desempregados. Assim, expectativas apontadas com o término do curso pelos estudantes são, prioritariamente, melhorar a qualificação profissional e a formação escolar, melhorar a qualidade de vida pessoal e da família e aumentar a renda familiar. A área da panificação tem rápida empregabilidade e possibilidade de atuação tanto a nível doméstico quanto empresarial, independente do porte do negócio, já que os conhecimentos científicos construídos e as habilidades desenvolvidas são as mesmas independentemente do formato da atuação do profissional.

Esse panorama de desordem, de heterogeneidade e da diferença possibilita e instiga a escola a experimentar novas formas de ser escola, pelo fato da necessidade de criar práticas pedagógicas inclusivas, o que gera a necessidade de políticas públicas que oportunizem e incentivem a oferta de PROEJA Ensino Fundamental, pois acredita-se que a partir do investimento no adulto, esse passará a investir na 
criança, que seguirá o curso passando de adolescente a jovem (BRASIL, 2007). Por isso, a escola deve servir como impulso para construção dos saberes que irão prover movimento à vida cotidiana, alterando assim a realidade social vigente.

Segundo Machado (2006), o PROEJA se estabelece e ganha significação nesse contexto de mudança paradigmática e de busca de universalização da educação básica, de ampliação de oportunidades de qualificação profissional e de perspectivas de continuidade de estudos em nível superior a um público portador de escolaridade inferior, fator limitante das chances de melhor inserção na vida social e no mundo do trabalho.

De acordo com o Ministério da Educação (BRASIL, 2007), o PROEJA objetiva a elevação da escolaridade integrada à formação inicial e continuada para o trabalho, buscando qualificar o egresso para a inserção positiva no mundo laboral por meio da possibilidade de disputar novos postos de trabalho nos quais possa desempenhar atividades complexas e dignas. Esse documento traz implícita em toda sua extensão a proposta que pode significar uma oportunidade ímpar para jovens e adultos que buscam retomar seus estudos, aumentar o nível de escolaridade e ao mesmo tempo investirem na profissionalização pessoal. Por esse motivo, a nível educacional, o currículo deve ser pensado em detalhes, pois a escola deve possibilitar o exercício da projeção da realidade vigente, envolvendo assim os múltiplos sujeitos, as múltiplas dimensões e as múltiplas instâncias.

É preciso pensar currículo como organização do conhecimento, já que as práticas escolares reproduzem as práticas sociais. Por isso, pensar currículo é pensar na infraestrutura, no planejamento e na formação dos professores, e é entender como o aluno aprende. E, uma forma de enfrentar esses pré-conceitos e incertezas relacionadas foi a oportunidade de um curso de capacitação aos professores de panificação do IFSC, já que todos possuem formação técnica. O curso Currículo Integrado: A Dialética entre a Educação Profissional e a Educação de Jovens e Adultos, com total de 120 horas de carga horária, objetivou a construção de saberes pedagógicos que dessem conta da especificidade do trabalho com Jovens e Adultos na perspectiva de formação integral, abordando, para isso, conteúdos como: o currículo integrado entre a formação geral e a formação profissional, os processos pedagógicos na integração curricular e teorias e práticas pedagógicas na integração curricular.

Observa-se, então, que o currículo deve ser culturalmente determinado, historicamente situado e não pode ser desvinculado da realidade social dos seus receptores. Por isso, integrar currículo, trabalho e sociedade é um desafio. Desafio que se configura nas ações pedagógicas, não se restringindo ao espaço da sala de aula. Portanto, para que o ensino se efetive é necessário refletir sobre currículo e a sociedade em que se vive, com o propósito de redimensionar o tempo e o espaço, pois a escola tem o desafio de orientar estes conhecimentos, preparando o sujeito para criar, se ajustar, aprender e operar as condições oferecidas no mundo do trabalho.

O currículo é um instrumento articulador que deve oportunizar o contato do aluno com os conhecimentos, convivendo e refletindo sobre questões relacionadas à vida individual, familiar e social. Assim, a proposta curricular deve respeitar e estar associada ao espaço e ao tempo do exercício, devendo interligar aspectos globais e informações explicitadas pela sociedade. Com esses conhecimentos, a partir da problemática da vida cotidiana que é um reflexo da sociedade, o aluno desenvolve processo crítico de construção cidadã. Isso demonstra que o currículo é um processo e por isso está sempre em ação, não podendo ser estático. Deve estar sempre acompanhando o momento e o perfil do aluno, considerando as especificidades 
do público alvo, no tempo e no espaço, partindo da bagagem e da experiência de vida do educando, que deve ser reconhecido como sujeito, e adaptando a estratégia didática de forma articulada com os princípios pedagógicos.

Considerando-se a identidade própria da EJA, aponta-se essencialmente para se delinear e se constituir uma política e/ou prática educacional que possibilite algum sucesso no processo educativo da EJA, que sejam "valorizados" os seguintes itens: as situações e os perfis dos estudantes, as faixas etárias desse alunado e, sobretudo, que seja aplicado o Princípio da Diferença, ou seja, a identificação e o reconhecimento da alteridade própria e inseparável dos jovens e dos adultos em seu processo formativo, da valorização do mérito de cada qual e do desenvolvimento de seus conhecimentos e valores (GEVAERD, OLIVEIRA, 2010).

A partir do estudo do perfil do aluno e da capacitação docente com relação à importância e estruturação do currículo, ou seja, a partir da vivência da atividade escolar com a vivência da prática profissional, indicou-se quais unidades curriculares profissionais deveriam ser contempladas na grade curricular do curso, sendo as selecionadas: Panificação Básica; Higiene e Manipulação de Alimentos; Educação Ambiental e Ética Profissional, além das prescritas pelo ensino fundamental: Matemática; Ciências; História; Geografia; Português; Inglês; Filosofia; Artes e Educação Física, e indicou também como deveria ser a dinâmica dos princípios políticos-pedagógicos adotados.

Neste curso de FIC Habilidades Básicas em Panificação, em parceria integrada ao Ensino fundamental, cada unidade curricular tem o desafio de sensibilizar o aluno para determinados conhecimentos, encontrando, para isso, inúmeros obstáculos de abordagem didático-pedagógica, devido às inúmeras particularidades que fazem parte do perfil do aluno de PROEJA, como nos exemplos que seguem.

Para entendimento da panificação é necessário compreender aspectos básicos sobre o trigo, o principal ingrediente. Isso evidencia entender conhecimentos com relação à procedência e às características tecnológicas da farinha de trigo, $\mathrm{o}$ que está intrinsecamente relacionado aos conteúdos de Geografia, História e Ciências. Mas, para a panificação, a Matemática também é de fundamental importância, pois a formulação precisa ser mensurada e convertida com auxílio de cálculos matemáticos elementares, regras de três e porcentagem.

Um ingrediente enriquecedor muito utilizado na elaboração dos pães é o ovo, por isso faz-se necessário abordar aspectos sobre higienização, limitação de ingestão para a saúde, procedência, efeitos de coloração e plasticidade nos produtos. A maioria dos alunos PROEJA desconhece a procedência do ovo de galinha e como um ovo pode chegar até a mesa para ser consumido ou tornar-se uma ave, o que é bem diferente do processo de outros animais como nos mamíferos. Esse é um exemplo simples que comprova a necessidade de integração com a unidade curricular Ciências.

Outro exemplo que evidencia dificuldade é a deficiência dos conhecimentos básicos, uma vez que os alunos, em muitos momentos, não conseguem estabelecer relação entre o tema abordado na aula de panificação e o conteúdo do ensino fundamental. E, o Português é, por certo, a maior dificuldade para o desenvolvimento completo das aulas práticas e teóricas, uma vez que a falta da compreensão de textos, a insegurança na leitura e até mesmo a incerteza do que está sendo lido impede o máximo aproveitamento do curso. É preciso desenvolver no aluno a autonomia de leitura, para que ele continue lendo depois de concluir os estudos, já que o ensino sem leitura é mera certificação, e não produz efeitos concretos na vida pessoal e profissional do jovem adulto (MOLL, 2008). Aprender o exercício da leitura para ser um cidadão capaz de ler o mundo, em todos os âmbitos e contextos. 
Esses exemplos demonstram o verdadeiro panorama com relação ao perfil dos alunos do PROEJA, uma grande experiência de vida em busca de capacitação profissional e aumento do grau de escolaridade. Os alunos buscam conhecimentos e saberes que os ajudem a fazer uma leitura do mundo, literal e metaforicamente, mais aprimorada.

Face às evidências de anos de afastamento escolar e um retorno com grande esforço à permanência na escola, as unidades curriculares têm um grande desafio com relação à integração e à persuasão de forma cativante e prática à assimilação dos conteúdos e saberes, o exercício da práxis, ou seja, praticar as ações e desenvolver as habilidades de forma consciente, com o respaldo dos conhecimentos teórico-científicos.

Por isso, o contexto vigente instigou a providência de algumas ações institucionais, de forma a sustentar o movimento de permanência e êxito do aluno na escola, como no caso da parceria entre a Prefeitura Municipal de São José e o IFSC, onde a primeira ficou responsável pelo transporte dos alunos, uma vez por semana, para as aulas de cunho profissional e a segunda ficou responsável pela bolsa assistência ao educando no valor de $\mathrm{R} \$ 100,00$ (cem reais), uniforme completo específico para a atividade de panificação, além dos insumos para as aulas práticas.

Pelo fato da abertura dessa primeira turma ter sido tão promissora, houve continuidade da oferta para outras turmas, porém em parceria com outros municípios: Tijucas e Itapema (Ensino fundamental com o Curso de Panificação), Florianópolis (Ensino Técnico nível médio com o Curso de Panificação e Confeitaria) e Florianópolis (Ensino fundamental com o Curso de Panificação e Confeitaria). O processo institucional vem sendo aprimorado ao longo da oferta periódica, mas algo que se mantém e que tem dado bons resultados entre instituições parceiras são os encontros político-pedagógicos com o acompanhamento dos alunos, uma forma de minimizar a evasão e monitorar a frequência e o aproveitamento do grupo discente, além de aproximar a integração interdisciplinar entre docentes das diversas áreas de conhecimento.

Aos alunos do PROEJA não falta idealismo sonhador em busca de um futuro melhor e boa vontade, além de serem interessados nas descobertas da ciência que explica os fenômenos mais corriqueiros do dia-a-dia, o que estimula e entusiasma o processo de ensino-aprendizagem. Eles serão futuros profissionais que, ao ingressarem no mercado de trabalho, estarão conscientes e capacitados na área de panificação e, por isso, terão um diferencial à empregabilidade. 


\section{Considerações Finais}

Assim, diante das dificuldades relatadas, fica evidente que deve haver uma mobilização para que o currículo seja efetivamente prático e consiga integrar as atividades escolares com a sociedade e o mundo do trabalho, contextualizando os saberes aplicando-os às vivências reais dos educandos - práxis vivenciada. A formação desses estudantes deve ser pensada em conjunto com as suas experiências práticas aprendidas na vivência diária, possibilitando-lhes capacidades efetivas, para lhes induzir uma postura cidadã atuante e emancipatória, na família, no mercado de trabalho e na sociedade como um todo, ou seja, ensino-aprendizagem caracteriza-se como sendo um processo contínuo, vivenciado tanto pelos discentes quanto pelos docentes. 


\section{Referências Bibliográficas}

BRASIL. Ministério da Educação. Proeja: programa nacional de integração da educação profissional com a educação básica na modalidade de educação de jovens e adultos: formação inicial e continuada: ensino fundamental. Brasília: MEC, 2007.

DURANTE, M. Alfabetização de adultos: leitura e produção de textos. Porto Alegre, RS: Artes Médicas, 1998.

GEVAERD, E. A. P.; OLIVEIRA, S. D. PROEJA - O Aluno. Florianópolis: IF-SC, 2010.

IBGE. Disponível em <http://www.ibge.gov.br>. Acesso em 05.08.13.

MACHADO, L. Proeja: o significado socioeconômico e o desafio da construção de um currículo inovador. In: MINISTÉRIO DA EDUCAÇÃO. Secretaria de Educação à distância. Eja: formação técnica integrada ao ensino médio. [Brasília, DF]: MEC/SETEC, 2006. bol. 16, programa 2, p. 37.

MOLL, J. Educação de jovens e adultos. Porto Alegre: Mediação, 2008.

NÓVOA, Antônio. A formação tem de passar por aqui: as histórias de vida no projeto Prosalus. In: Nóvoa, A e Finger, M., orgs. O método (auto) biográfico e a formação. Lisboa: M. Saúde, 1988.

OLIVEIRA, M. K. Jovens e adultos como sujeitos de aprendizagem. In: RIBEIRO, V. M. Educação de jovens e adultos- novos leitores, novas leituras. Campinas: Mercado de Letras, 2002.

OLIVEIRA, M. K. Jovens e adultos como sujeitos de conhecimento e aprendizagem. Trabalho apresentado na 22 ${ }^{\mathrm{a}}$ Reunião Anual da ANPED. Caxambu: 1999 .

RIBEIRO, V. M. Educação de jovens e adultos - novos leitores, novas leituras. Campinas: Ação Educativa, 2008. 
ROSA, A. C. S. da, PRADO, E. Educação de jovens e adultos: as dimensões política, profissional e pessoal na formação docente. Revista Olhar de Professor, Ponta Grossa, 10(2): 103-122, 2008. Disponível em <http://www.uepg.br/olhardeprofessor $>$. Acesso em 01.05.09.

SANTOS, S. V. dos. O Proeja e o desafio das heterogeneidades. In: MINISTÉRIO DA EDUCAÇÃO. Secretaria de Educação à distância. Eja: formação técnica integrada ao ensino médio. [Brasília, DF]: MEC/SETEC, 2006. bol. 16, programa 3, p. 54.

SILVA, T. T. Documentos de Identidade - Uma introdução às teorias do currrículo. Belo Horizonte: Autêntica, 1999. 